\title{
Filigrane
}

Écoutes psychanalytiques

\section{Samuel Pereg}

\section{Marie Hazan}

Volume 27, numéro 1, 2018

URI : https://id.erudit.org/iderudit/1055608ar

DOI : https://doi.org/10.7202/1055608ar

Aller au sommaire du numéro

\section{Éditeur(s)}

Revue Santé mentale au Québec

\section{ISSN}

1192-1412 (imprimé)

1911-4656 (numérique)

Découvrir la revue

\section{Citer ce document}

Hazan, M. (2018). Samuel Pereg. Filigrane, 27(1), 125-127.

https://doi.org/10.7202/1055608ar d'utilisation que vous pouvez consulter en ligne.

https://apropos.erudit.org/fr/usagers/politique-dutilisation/ 


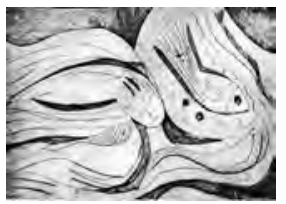

\title{
Samuel Pereg
}

\author{
Marie Hazan
}

amuel Pereg nous a quittés. Il est décédé le 3 mai 2018 à Montréal. Professeur de 1970 à 1994, année à laquelle il a pris sa retraite de l'UQAM, pionnier au Département de psychologie, il a fait partie de ses fondateurs et de ses personnalités marquantes...

Né le 21 janvier 1934 à Sofia en Bulgarie au moment de la montée du fascisme et du nazisme en Europe, Samuel Pereg, sa sœur et ses parents ont fait partie des Juifs de Bulgarie qui ont été sauvés in extremis de la barbarie nazie, de la déportation et de la destruction ${ }^{1}$. Sa famille a ensuite émigré en Palestine après la Deuxième Guerre mondiale, au moment de la fondation de l'État d'Israël. Par la suite, il est allé en Angleterre, puis en France, où il a rencontré sa future épouse, Jacqueline, qui l'a amené au Québec, loin de ces tourmentes. Il était difficile de croire que le français était sa troisième langue, après le bulgare et l'hébreu! Après une enfance et une adolescence tourmentées et secouées par l'histoire, être étudiant en France devait être vivifiant, et le Québec, qu'il adopte comme pays dans les années soixante, un havre de paix bien choisi!

Samuel Pereg étant parti à la retraite en janvier 1994, les étudiants actuellement dans le programme et la plupart des collègues ne l'ont donc pas connu directement. Personnage marquant, il était respecté et apprécié des étudiants et du milieu de la psychologie, et de ce que l'on appelait alors «la marge psychanalytique».

La première fois que j'ai rencontré Samuel était à mon entrevue d'embauche pour la section psychodynamique du Département de psychologie de l'UQAM. Il en était le «responsable» selon la formule consacrée. C'était en mai 1987 et j'étais alors enceinte de mon premier bébé.

J'ai adoré être membre de cette section compacte et soudée, "tricotée serrée», même si cette dimension a légèrement changé par la suite. Ce sentiment très fort me rappelait le militantisme, l'engagement et la solidarité des années 70, non sans la prévalence d'un surmoi de groupe, parfois intense $^{2}$. Samuel a grandement contribué à pacifier les choses, tenant une position ferme, mais pas trop polémique, en cette période de "guéguerre» 
départementale. Il faisait figure de leader soft et suscitait sympathie et respect. Notre sentiment d'identité et d'appartenance à ce groupe, tout compte fait plutôt hétérogène, relevait d'une affiliation qui gommait nos diverses différences. Il faut dire que notre section était plurielle au niveau des origines et des accents.

La formation en sections a été d'ailleurs salutaire dans cette période épique qu'on m’a décrite, mais dont je n'ai connu que les derniers reflux, à partir de 1987.

Étions-nous, comme disait Hélène Richard, assiégés et solidaires dans un petit village gaulois? C'était en quelque sorte le récit mythique qui nous tenait ensemble, comme l'idée de faire partie d'une famille, bien qu'elle puisse être un peu dysfonctionnelle.

J'ai partagé avec Samuel une longue amitié ponctuée d'événements psychanalytiques: la vie de la section durant mes premières années comme professeure, mais aussi la fondation du Groupe d'études psychanalytiques interdisciplinaires (GÉPI) ${ }^{3}$ et l'organisation de colloques ${ }^{4}$, l'enseignement en team-teaching du séminaire sectoriel sur le thème de l'interprétation pendant deux années d'affilée et les comités et jurys de thèse.

D'autres discussions intenses avec Samuel portaient sur la judéité, le judaïsme, la politique d'Israël, la Shoah et ses relations compliquées avec l'identité juive, complexe et tourmentée, toujours questionnée et réitérée, rejetée et chérie en même temps.

Marqué par sa judéité, une identité imposée dans son enfance en Bulgarie et son adolescence en Israël où il a découvert qu'il était sépharade et - disait-il - citoyen de seconde catégorie, il en gardait une colère, une révolte même, contre l'«establishment» et les religieux... A-t-il souhaité s'en éloigner? Malgré cette distance, ce rejet même parfois, à l'instar de son propre père il restait juif de manière insistante, comme une question ouverte et irrésolue.

Marie Hazan

hazan.marie@uqam.ca

\section{Notes}

1. Voir Morel, O. (s. d.). Comment la communauté juive de Bulgarie fut sauvée du génocide. Un exemple d'action non violente réussie injustement ignoré. Repéré à https://www. editions-harmattan.fr/auteurs/article_pop.asp?no=2474\&no_artiste=1235 et Sauvetage des Juifs de Bulgarie. (s. d.). Dans Wikipédia, l’encyclopédie libre. Repéré le 14 août 2018 à https://fr.wikipedia.org/wiki/Sauvetage_des_Juifs_de_Bulgarie 
2. En 1987, les membres de la section psycho-dynamique-humaniste étaient: René Bernèche, Irène Bleton, Nicolaï Buriana, Paul Frappier, Marie Hazan, Mireille Lafortune, Robert Letendre, Pierre Michaud, Hans Neidhart, Samuel Pereg, Sandra Rafman, Hélène Richard et moi-même.

3. Le GÉPI a été fondé à l'initiative d'Hélène Richard en 1988 et comprenait des membres de la section et des professeurs d'autres départements de l'UQAM (principalement).

4. À l'initiative de Samuel Pereg, le GÉPI avait organisé un colloque inter-universitaire israélo-québécois le 29 août 1992 à l'UQAM. Les participants étaient: Ada Abraham, Yolanda Campbel, Samuel Pereg, Simon Harel, Hélène Richard et Judith Stern, et les animateurs des deux tables rondes Serge Arpin et moi-même. 